\title{
Conceptualizing Time in Archaeology: A Study of the Igbo of Nigeria
}

\author{
Pamela Ifeoma Eze-Uzomaka \\ Department of Archaeology and Tourism, University of Nigeria, Nsukka, Nigeria
}

\section{Email address:}

drpamela26ayahoo.com

\section{To cite this article:}

Pamela Ifeoma Eze-Uzomaka. Conceptualizing Time in Archaeology: A Study of the Igbo of Nigeria. Advances in Sciences and Humanities. Vol. 4, No. 5, 2018, pp. 62-67. doi: 10.11648/j.ash.20180405.11

Received: October 25, 2018; Accepted: November 20, 2018; Published: December 26, 2018

\begin{abstract}
Archaeologists are very concerned with chronology and the measurement of time especially as it affects linear time. This is because all archaeological finds are usually dated, so that they can have lasting significance. In a bid to bring stability and sagacity to the archaeological practice, archaeologists have extensively employed the use of chronology, frequently using agreed measures of time to construct prehistory. However the concept of time in indigenous communities is a far cry from "time" as observed by professional archaeologists. The objective of this study is to to determine the historical awareness of cultures and indigenous people and examine their characteristic way of observing time, which is indicative of their peculiar philosophy of life. For this study, the methodology used was the ethnographic research approach, which involved in-depth interviews. To achieve this objective, purposive judgemental sampling method was used to guarantee that a definite class of knowledgeable people are represented in the study. Using the Nkwerre indigenous society as a case study, the results of this research demonstrate that the application of time is culture bound. The event is more important than the actual time it took place. It is concluded that Western societies have a different assessment of time as opposed to non-Western societies. This paper is therefore, an analytical reflection on how the Igbo of Nigeria perceive time.
\end{abstract}

Keywords: Culture, Indigenous, Concept, Chronology, Calendar

\section{Introduction}

The concept of time in the past is crucial since it regulates the ancient consciousness of various cultural entities. Some of the earliest, most popular quotes on the importance of time in the archaeological context elucidated the fact that "Any inquiry into the past which does not reckon with the dimension of time is obviously nonsense; the past is the past by virtue of the place it occupies in the time-scale" [16]. In the past, archaeologists have reflected extensively on the nature and conceptualization of time especially by those whose pasts they have studied $[1,2]$. Time is of prime importance to Archaeology because; Archaeology is a study of the past and the past is measured in time. On the other hand, a number of social anthropologists have studied the perceptions of time in contemporary societies always seeking to understand the reckoning of time among different cultures especially in relation to the measurement of time in the western world $[11,15]$.

Archaeologists measure time by utilizing chronology, which is divided into two main categories: Absolute dating and relative dating methods. Many years of using chronometric dating methods have made archaeologists more cautious in their presentation of absolute technologies because it has been known to fail. However, absolute dating methods have been at the forefront of Archaeological chronology. In addition, relative dating methods have been used for decades in measuring time in the archaeological past. A summary of absolute and relative dating methods is given below (Table 1): -

Table 1. A summary of some dating methods in Archaeology.

\begin{tabular}{ll}
\hline Absolute Dating Methods & Relative Dating Methods \\
\hline Radiocarbon dating $C^{14}$ & Stratigraphy \\
Amino Acid racemization & Seriation \\
The rmoluninescence & Typology \\
Archaeomagnetic dating & Cross cultural dating \\
Potassium Argon dating & Linguistic \\
Fission Track dating & Fauna and Flora including Bone \\
\hline
\end{tabular}




\begin{tabular}{ll}
\hline Absolute Dating Methods & Relative Dating Methods \\
\hline Electron Spin resonance & The use of climate \\
Dendrochronology (Tree ring dating) & Law of superimposition \\
Herbchronology & Morphology \\
Obsidian Hydration dating & Fluorine absorption dating etc. \\
\hline
\end{tabular}

In the past, techniques of dating depended on the use of historical methods whereby calendars and chronologies of ancient people were employed by archaeologists to enable them date the sites especially in cases where copious amount of artifacts have been recovered. This was in used in places like Egypt, Mesopotamia, the Mayas and other early civilizations. What sets time perspectives apart from other approaches, is the insistence on readings of the archaeological record as a unique historical data set on which to base multiple scales of explanation [9]. Scholars have written several essays referring to this unique data in their various publications [10,7]. Others discussed a variety of approaches to time, showing clearly that the questions about classic time in Anthropology refer to the social conceptualization of time [6].

An investigation into how indigenous societies conceptualize time, shows that conceptions of time in ethnographic societies is linked to the temporal structure of individuals or household cycles. Social memory in societal reproductions is key to unravelling the way things work for social entities like communities. It was therefore important to study how societies related to the material and non-material past, to be better able to understand the specific manifestations of their attitude to time and the past. It is imperative at this juncture to explain that I personally engage archaeological time measurement in my profession but still find a need to present the viewpoint of indigenous people in their cultural setting.

\section{Methodology}

Qualitative methods were used for this study since they are less structured and are able to respond more to the state of the respondents than quantitative methods with its emphasis on numbers. Interviews were extracted from 15 respondents using ethnographic methods, which yield large volumes of rich data obtained from few people. The sample size was limited to the few people who were knowledgeable of the topic on "Time". The Igbo peoples' conception and understanding of the past was considered, using Nkwerre as a test ground for the rest of the Igbo people of Nigeria. A single Igbo group (Nkwerre) was used because the Igbo language has different words for different aspects of time in different Igbo groups. Ethnographic studies of the Igbo of Nigeria incorporated a holistic appraisal of the life of the Nkwerre people. Complementing oral histories and documentary sources were also examined. While formulating the sensitizing concepts that would act as the framework of this study, an extensive review of relevant literature was conducted on many aspects including the theoretical approach to the research. The survey in Nkwerre was carried out based on the information that is relevant to the rest of Igboland. This research is centered on people. They had a story to tell about what they believe is their past and this story is fast fading away as many of the custodians of this knowledge pass away.

\subsection{Indigenous Conceptualizations of Time}

The subject of time in the study of anthropology/archaeology is a problem, which has a distinct difficulty in finding a Meta language that could "conceptualize something so ordinary and apparently transparent in every day life" [15]. Time is described as having a "chameleonic character" upon which "our theoretical understanding of temporality hinge on the way we conceptualize its connections to space, action and actor" [15]. The annual calendar has been taken over by people who seek to exercise authority over the chronological definition of timing and the sequence of daily as well as seasonal activities. Chronological instruments like "clock time" control various aspects of people's everyday life. Such instruments of time also connect people to the universe and enable them to control critical values and potencies in which governance or politics is operated. It then follows that as long as one controls the media of time, one can also control the wider order of socio-political changes that militate in the lives of people. Time if studied from this point of view would therefore make meaning in the sense of 'world time' rather than only focusing on the different perceptions of different people.

African people regard time as a combination of events. The classification of time is two dimensional in the African thought [14]. Time has a long past and a present. It does not really have a future. There is no future as such because the events there have not yet taken place and do not intend to do so in the immediate future. They cannot be realized and therefore they cannot constitute time. The future does not have the solidity of a factual event. Time has to be experienced to have meaning in life. What is in the future has not taken place and is not really part of time except if it falls within the cyclical rhythm of natural phenomena. This is where the difference begins with the concept of time in western thought with an indefinite past, a present and an indefinite future. At present, some Africans have become so westernized in their thought process, that they no longer know such indigenous conception of time.

Africans do realize that "myth proper, lacks a chronology in the strict sense... significance is to be discerned only in the relations between the component parts of the story, sequence is simply a persistent rearrangement of elements which are present from the start" [13]. Myths have their own place in African history. They are never substituted for the historical, the way some scholars do when reporting their findings. Western societies have a different view of time and social systems from non-western societies. For most indigenous people "it is the year's round itself which provides the measure of time" [12]. 


\subsection{The Nkwerre of Nigeria}

The Nkwerre people are part of the Igbo peoples of Eastern Nigeria (see Figure 1). Linguistic studies on that part of Nigeria group their language among the Kwa sub-group of languages in the Niger-Congo family. In the past, before the British colonialists invaded them, the Nkwerre were initially farmers and later they became traders. Nkwerre is a community that may have practiced iron smelting in the past and in more recent years, were involved in iron smithing for the purposes of gun making. They were not just famous as blacksmiths but were also long distance traders. Before trading started in Nkwerre, agriculture was their main source of income. The people were peasant farmers and the men were involved in hunting as a pastime and a source of meat for the family. Local trading was said to have started as a matter of necessity. It was said that when people needed different farm produce from others, they traded their goods by barter. If for instance, fish farmers needed some salt or some palm produce, they would go to the local market and exchange goods giving what they had in surplus for what they lacked. There were local markets, which took care of the daily needs of the people of Nkwerre. There were four days in the traditional week and these markets were conducted on one of the traditional days of the week. The weekdays were Nkwo, Eke, Orie and Afor. The four days were referred to as izu nta (shorter market week). There was also an eight-day week made up of the same days of the week but counted twice over, to make up the eight days. This was referred to as $i z u$ ukwu (longer market week). There were many local markets in the pre-colonial days and some of them have survived to date.

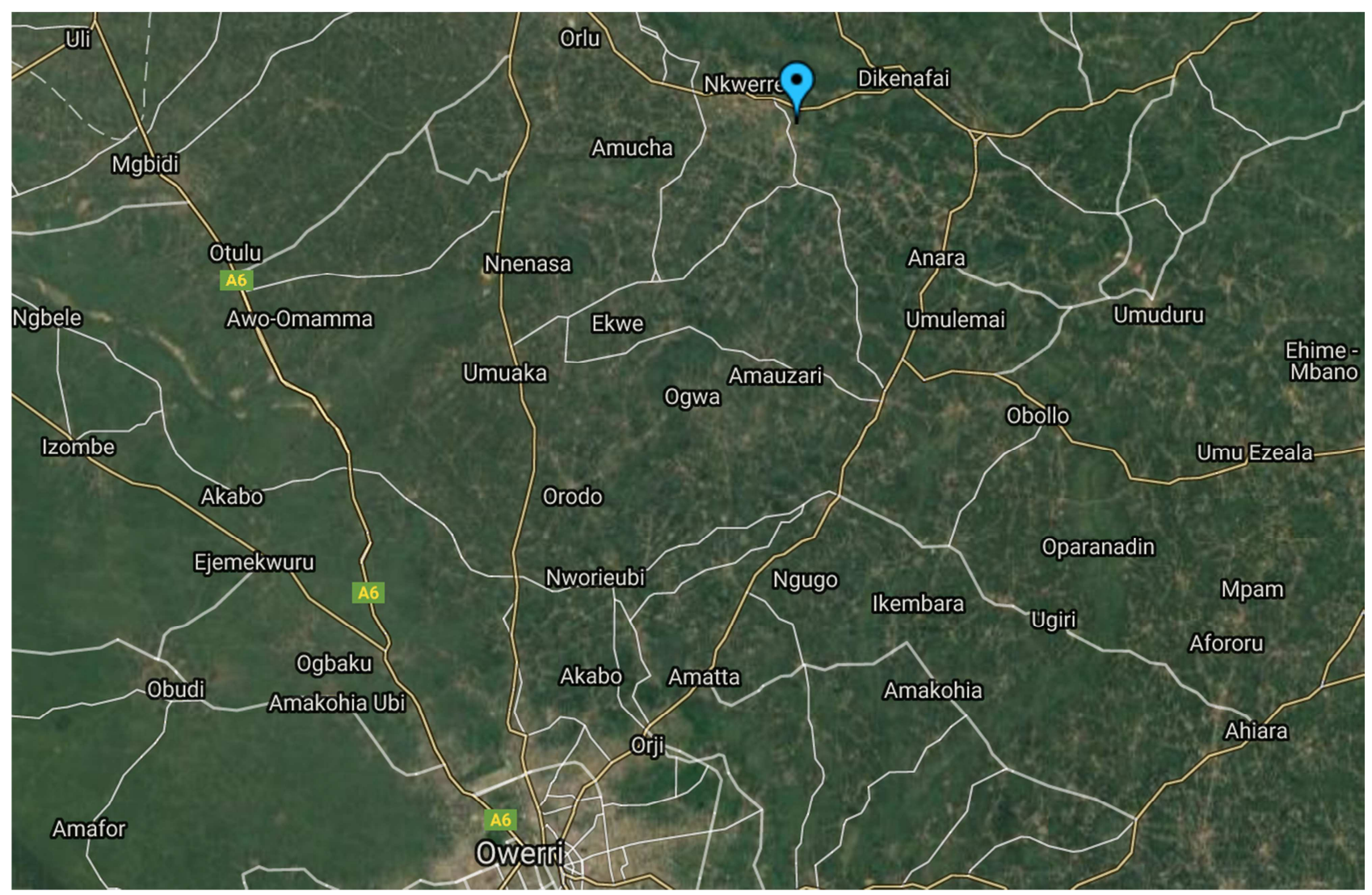

Figure 1. Location of Nkwerre (http://www.maplandia.com/nigeria/imo/ideato/nkwerre/).

\subsection{Conception of Time in the Nkwerre Past}

Before 1600 A. D. when contact with Europeans became more commonplace, perception of time in the indigenous Nkwerre society was different from the way, which it was perceived at present. As one of the societies that did not use Western oriented clocks and time measuring pieces, the people in the Nkwerre past devised other means of communicating a sense of time to the members of their community. At that time, they did not have foreign calendars or clocks yet they seem to have had their own unique time projections (they adopted the use of time keeping gadgets after their contact with the Portuguese in the $15^{\text {th }}$ century).
Before that time however, these indigenous people conducted their affairs based on some notion of time and used a calendar of events. Time depended on the instruments that were used to measure it. Measuring time in the Nkwerre past turned out to be a very delicate undertaking. Time was more clearly marked by events than by actual numerical or mathematical time. During fieldwork, respondents preferred to discuss a timetable of events rather than the use of the Gregorian calendar. They wanted to discuss events and explain when they actually took place, rather than affix numerical time to past events. On the other hand, events that occurred after the advent of writing in Nkwerre did not seem 
to present this problem as dates were easily recalled.

\subsection{Indigenous Time Measurement}

Time was measured using an annual traditional/ritual calendar of events. This calendar was agricultural in nature since the people of Nkwerre were at that time predominantly peasant farmers. This calendar also affected all the traditional festivals that were linked to the agricultural cycle. The annual calendar usually started at the "time for clearing" known in the local dialect as "oge isu oru". The Nkwerre calendar commenced with the clearing of the farmland for planting. This took place in March. That period is therefore the first month, (onwa mbu). At the beginning of the traditional calendar, the priests used to offer sacrifices to Ajimiri, the chief deity, and this done under the huge tree at Nkwo (market place) of Nkwerre known as okpuru abosi. These sacrifices were meant to solicit the help of the gods during the planting season to prevent problems with the planting of yams; through the clearing of the land, planting, to the period of harvesting of crops. In the distant Nkwerre past, festivities that marked the onset of the cyclical calendar usually commenced with the offering of sacrifices to all the gods while fields were cleared in preparation for farming. Clearing of fields later coincided with the month of March in the European calendar, the planting season coincided with April and May, harvest of grains was in July, yam harvest in August, and the agricultural dance festival, Amuma, in October (See Table 2).

Table 2. Calendar of annual events in the Nkwerre past [5].

\begin{tabular}{|c|c|c|c|}
\hline European calendar & Traditional Calendar & Local celebration & Agricultural season \\
\hline March & Onwa mbu (First month) & $\begin{array}{l}\text { oge-isu-oru Clearing (Sacrifices to } \\
\text { Ahajioku) }\end{array}$ & (First month) (Bush clearing) \\
\hline April - May & Onwa ano (Fourth month) & $\begin{array}{l}\text { Mmeme - mbamoru also known as Mgbasu } \\
\text { Ekpe. (Festival of the planting season) }\end{array}$ & Planting season, farming (Period of famine) \\
\hline July & Onwa ise (Fifth month) & Oriri nkpuru oka (Harvest of grains) & $\begin{array}{l}\text { The season for the eating of corn, usually celebrated } \\
\text { in preparation for the new yam festival }\end{array}$ \\
\hline July - August & & Nkwo ukutu, Iriji or (New yam festival) & Harvesting of new yams called Ogugu ji \\
\hline
\end{tabular}

The calendar was also lunar in nature. The sighting of the new moon was a major event that determined the timing of festivities. The Nkwerre calendar was not like the European calendar. They had a farming calendar and a lunar calendar that were counted and observed together but never came in conflict with one another. It usually started around March and terminated in October of the present European calendar.

\section{Result}

From the research conducted, it was discovered that time in the indigenous Nkwerre past depends on the instruments that are used to measure it. Humans have devised ways of dividing, expressing, measuring, and recollecting the passage of time. To do this, various devices are employed which in themselves do not mean anything except for the use that people have ascribed to them. An early work on this shows that there is no way by which we can conceive time except by distinguishing its different moments [4]. These differentiations seem to be embedded in an impersonal frame with divisions into days, weeks, months, years, etc., corresponding to the periodical recurrence of feasts and public ceremonies. A calendar is a means of expressing the rhythm of collective activities, and at the same time retaining the sole function of ensuring the regularity of these activities. It becomes clear that time exists for us because we are social beings. The mysterious way, in which time seems to encompass everything, reveals the social origins of time because society also has the tendency of encompassing everything [4].

In the Nkwerre past, time was measured using instruments provided by nature. The sun served as time measurement using the shadows thrown by a person. When the shadows were tall, it was morning. When they became short, it was afternoon. At the time when the shadows were just at one's feet, it was noon. As they become tall again with less heat, it was evening time. Once they disappeared, it was night. Animals were also used to help humans keep time. The cock announced the morning and the owl announced the night. Birds were also said to announce time in seasons. Some birds migrate away during some seasons and others came at other seasons. People in the early days studied these birds and used them to tell time. The bush pigeon was said to be a prompt timekeeper in prehistoric times. They return home to roost at certain times of the day. Insects were also known as agents of time. In their seasons, they made different noises that were representative of the time and the season. Respondents agreed that the cockcrow in the morning was the most reliable timepiece and was used to represent the dawning of a new day. These are the different means of nature through which people in the past-recognized time. The last and perhaps the most interesting, is the use of flowers to tell time: - people in Igboland watched some trees and when the flower opened up it was around $4 \mathrm{pm}$ or $5 \mathrm{pm}$. The flower was later called the 4 o'clock flower when clocks came into use. The botanical name of this flower is Mira midis gelata.

Time was therefore perceived communally although it was experienced individually. Time was created and measured by the people's social activities and was a product of their various experiences. As a community, the people in the Nkwerre past recognized the need to measure time so as to synchronize their activities through space but did not have to 
resort to time measurement in other societies to be able to implement time in their own locality which also included the rest of Igboland as was explained by the respondent above.

People's historical consciousness seemed to be fixed on big moments and these acted as pegs in the people's minds. For example, there was a definite time of origin, the time of the British invasion into Nkwerre and a vague chronology of existence in between these two. Some of the activities that took place in the interim were epidemics as well as wars and skirmishes, during which lands were acquired from neighbouring towns. The details of these events are not recounted in the text at the request of the respondents. However, any insistence on ascertaining when certain events took place made some of the respondents uncomfortable since at times they could not remember and at other times they preferred to forget.

Social memory plays a vital role in the recollections of any society/community, placing restrictions on what can and cannot be recalled publicly. Recollections can often be treated as a cultural responsibility rather than an individual activity and as such the responsibility for recollection is no longer personal, but becomes the collective responsibility of the community. Members of a society can therefore decide to share or refuse to share some social experiences based on initially agreed concepts. Their images of the past legitimize the present and as such, whatever they choose to recollect becomes very important to their existence in the present. It has been explained that: -

"Across generations, different sets of memories, frequently in the shape of implicit background narratives, will encounter each other; so that, although physically present to one another in a particular setting, the different generations may remain mentally and emotionally insulated, the memories of one generation locked irretrievably, as it were, in the brains and bodies of that generation" [3].

As a result of the above, memories become enclosed in public time. Public time therefore becomes not just "the planned creation of individuals but arises from habitual practice" [8]. It is as a result of these forces of habit, that social memory and the resultant public time, eventually becomes legitimized for whichever community that practices it.

\section{Discussion}

There are some important points to note in the concept of time in the Nkwerre past:

1. Time was measured using natural means;

2. Recollections of social events were communally controlled and sometimes involved "forgetting" painful memories;

3. The annual calendar depended entirely on agriculture. It was cyclical in nature and was not dependent on the western understanding of chronology;

4. It was up to the people responsible for it to announce the commencement of aspects of the calendar. Individuals could not decide when it was time for an agricultural event;

5. The calendar was event-controlled rather than by mathematical progression. Onwa ano (fourth month/month of famine) came after onwa mbu (first month/clearing of the agricultural farm). There was no numerical progression from first month to fourth month. The months listed were the first, fourth, fifth and sixth months. There were no second and third months, and no explanation was given for this misnomer. In addition there was no representation of the months of January, February, June, November and December. The assumption would then be that since the calendar in the Nkwerre past was basically based on the local farming seasons, the months of November to February were the periods for consumption of the harvest. June did not feature probably because the grains were not yet ready for harvest.

\section{Conclusion}

Archaeology is irretrievably bound up with time and is justified mostly by chronology. Most of the time, chronology of some sort (absolute, relative) is imperative in the interpretation of the archaeological past. Time is caught between the past and the present. Time exists in relation to the present and the absent. The past that we unearth during excavation belongs to time that is not in the present. In the social practice of archaeology, the past exists as a future project in the present, so that every activity in the past is in the present when its time is presented in the present. For the past to be, there is need for an interpreter (archaeologist) in the present. This interpreter did not live in the past but must preserve the past for the future in the present. The past must be re-described in the light of what happened thereafter without the input of the actors. The archaeologist therefore holds the past in relation to the present and becomes the executor of the laws of time, change and their coexistence with the present. The archaeologist must understand and interpret the developments of the past and thus mediates between the past and the present.

Time in archaeology is not just the calculation of absolutes, for example ${ }^{14} \mathrm{C}$ dates, neither can it be carried out with any particular cultural structure in mind. All conception of time should ideally be based on people and their cultural settings. Absolute or relative time should be dependent on culture and cannot be determined by foreign impositions or outside standards. Details of the application of time remain culture bound. In indigenous societies, the event is more important than the actual time it took place. The length of time is flexible and not rigid. A year for instance is not made up of 365 days. For indigenous people, harvests, festivals, fishing ceremonies and even the coming of the first rain measure time. People's consciousness is fixed on time of origin and time in the recent past. All aspects of time in the middle are usually hazy and often distorted. Genealogies do not consist of dates and measurement is usually not by chronometric sequence. 


\section{References}

[1] Bradley, R. (1991) Ritual, time and history. World Archaeology, 23: 209-19.

[2] Clark, G. (1992) Space, Time and Man: A Prehistorian's View. Cambridge: Cambridge University Press.

[3] Connerton, P. (1998) How Societies Remember. Cambridge: Cambridge University Press.

[4] Durkheim, E. (1915) The Elementary Forms of the Religious Life. London: Allen and Unwin.

[5] Eze-Uzomaka, P. I. (2000) Museums, Archaeologists and Indigenous People: Archaeology and the public in Nigeria. BAR International Series 904. Oxford: Basingstoke Press.

[6] Gell, A. (1992) The Anthropology of Time: Cultural Constructions of Temporal Maps and Images. Berg, Providence.

[7] Gingrich, A., Ochs, E. and A. Swedlund (2002) Repertoires of Timekeeping in Anthropology. Current Anthropology 43 (4): S3-S4.

[8] Gosden, C. (1994) Social Being and Time. Oxford: Blackwell.

[9] Holdaway, S. and L. Wandsnider (2008) Time in Archaeology: An Introduction. Anthropology Faculty Publications. University of Auckland and University of Nebraska - Lincoln.

[10] Karlsson, H. (2001) It's about Time: The Concept of Time in Archaeology. Bricoleur Press, Goteborg.

[11] Leach, E. R. (1954) Primitive Time-Reckoning. A History of Primitive Technology. London: Oxford University Press: 11027.

[12] Leach, E. R. (1961) Two essays concerning the symbolic representation of time. In E. R. Leach (ed.) Rethinking Anthropology. London. Atlone: 124-36.

[13] Leach, E. R. (1969) Genesis as Myth and Other Essays. London: Jonathan Cape.

[14] Mbiti, J. (1969) African Religions and Philosophy. London: Heinemann.

[15] Munn, N. D. (1992) The Cultural Anthropology of Time: A Critical Essay. Annual Review of Anthropology, 21: 93-123.

[16] Piggott, S. (1959) Approach to Archaeology. London: A and C Black. 